\title{
A INFLUENNCIA DOS PROCESSOS QUE BUSCAM A AUTOFORMAÇÃO: UMA LEITURA ATRAVÉS DA FENOMENOLOGIA E DA SEMIÓTICA SOCIAL*
}

\author{
The influence of processes that involve self-formation: \\ a reading through the Fenomenology and the Social Semiotics
}

\author{
Silvia Regina Quijadas Aro Zuliani ${ }^{1}$ \\ Dácio Rodney Hartwig ${ }^{2}$
}

Resumo: Os Estágios Supervisionados são disciplinas integradoras entre o conhecimento específico e os conhecimentos pedagógicos. Neste trabalho, apresentamos resultados de uma pesquisa realizada com Licenciandos em Química utilizando a Metodologia Investigativa. O objetivo foi buscar as percepções dos sujeitos a respeito da própria aprendizagem e sua transferência ao processo de ensino. Utilizou-se o referencial proposto pela Fenomenologia e Semiótica Social para a análise dos dados. Confirmaram-se o potencial da metodologia no desenvolvimento metacognitivo dos sujeitos e na evolução de suas concepções. Estes valorizam a construção de estratégias de aprendizagem como um processo pessoal e profissional. A reflexão levou-os a reconhecer a complementaridade entre ensinar e aprender, como processos indissociáveis, e geradores de conhecimentos aplicáveis à atividade profissional.

Palavras-chave: Prática de ensino de Química. Metodologia investigativa. Desenvolvimento metacognitivo. Fenomenologia. Formação de professores.

\begin{abstract}
Teaching Practices are integrative discipline between the specific knowledge and the pedagogical knowledge. In this work, we present the results of a research carried through with future teachers in Chemistry, using the Investigative Methodology. The objective was to seek the perceptions of the students about their own learning and its transference to the educational process. We used the benchmark proposed by the Phenomenology and Social Semiotic for the data analysis. It has confirmed the potential of the methodology in the students metacognitive development and in the evolution of their conceptions. They value the construction of learning strategies as a personal process and professional knowledge. The reflection led them to recognize the complementarity between teaching and learning processes inseparable, and its application to the professional activity.
\end{abstract}

Keywords: Practical of Chemistry Education. Investigative Methodology. Metacognitive Development. Fenomenology. Teachers formation.

* Agência financiadora: CNPQ.

${ }^{1}$ Química. Doutorado em Educação. Docente, Departamento de Educação, Faculdade de Ciências, Universidade Estadual Paulista Julio de Mesquita Filho (Unesp), campus de Bauru, SP. < silviazuliani@fc.unesp.br >.

${ }^{2}$ Licenciatura em Química. Doutorado em Educação. Docente, Departamento de Metodologia de Ensino, Universidade Federal de São Carlos (UFSCAR). São Carlos, SP. < hartwig@power.ufscar.br >.

${ }^{1}$ Av. Eng. Luiz Edmundo Carrijo Coube, n. 14-01

Bauru, SP

$17.033-360$

359

Ciência \&̊ Educação, v. 15, n. 2, p. 359-82, 2009 


\section{Introdução: características da construção da profissionalidade docente}

A discussão em torno da formação inicial de professores tem se desenvolvido de maneira intensa nos últimos anos e vem gerando uma literatura bastante abrangente. Entretanto, definir o que seja um "bom" professor e "como" formá-lo, está longe de se tornar uma realidade viável, tanto do ponto de vista das Instituições Formadoras como da complexidade do sistema de ensino. As Licenciaturas permanecem, em sua grande maioria, segundo Cunha (1996), sem muitas mudanças significativas em seus modelos originais, isto é, constituídas de dois focos separados e desconexos, ou seja, as disciplinas de conteúdo específico e as disciplinas pedagógicas.

Para Schnetzler (2002), os únicos momentos da formação que procuram fazer a ligação entre ambas são as práticas de ensino e similares. Nestas disciplinas, o professor, que normalmente apresenta formação na disciplina específica em questão e pós-graduação na área de educação, é que "tenta" fazer a ponte de ligação entre os dois eixos da formação que permaneceram caminhando em paralelo durante toda a licenciatura.

De acordo com Vieira da Silva (2006), algumas Licenciaturas estão tentando alterar esta situação:

[...] de um modo geral, percebe-se que, entre os cursos analisados (duas universidades estaduais paulistas e duas universidades federais), uma paulista e uma de Minas Gerais estão de acordo com a legislação atual, sobre a distribuição de carga horária proposta para os cursos de formação de professores da Educação Básica em nível superior. (p. 91).

Nos quatro cursos analisados encontrou-se as disciplinas interdisciplinares mais clássicas, como Didática, Instrumentação Para o Ensino de Química, Metodologia de Ensino de Química e Estágio Supervisionado em Química. Encontrou-se também, em pelo menos três dos cursos analisados, outras disciplinas interdisciplinares menos comuns, como História da Química e Química Para O Ensino Médio ou Elaboração de Material Didático Para O Ensino de Química e Ciências. Mas, o que chamou a atenção foi a presença de um número elevado de disciplinas interdisciplinares com caráter específico nos cursos na Federal de São Paulo e uma das Universidades Estaduais do São Paulo, principalmente neste último. Entre elas estão, por exemplo, Físico-Química de Equilíbrio, Introdução à Química Ambiental, Física Experimental, Mineralogia, Bioquímica, entre outras. (VIEIRA DA SILVA, 2006, p. 92)

Ao nos questionarmos sobre as razões para esta dicotomização nas licenciaturas, podemos recorrer novamente ao texto de Cunha (1996), que as associa à tradição histórica e aos valores que condicionam a manutenção e continuidade das comunidades científicas. A partir destas reflexões, pode-se prever que a prática destes futuros professores será baseada fundamentalmente na utilização dos métodos de ensino utilizados em sua própria formação (SHNETZLER, 2002). A dicotomia existente no modelo tende a isolar o mundo acadêmico 
do mundo da prática, considerando-a como menos importante no processo de elaboração dos conhecimentos do futuro professor. O professor em formação deve ser instigado a refletir num processo de investigação da prática, a partir da qual se dará a construção e renovação de seus saberes sobre ela.

Para Perez Gomes (1992, p. 102), esta ação dá-se da seguinte maneira:

[...] parte-se da análise das práticas dos professores quando enfrentam problemas complexos da vida escolar para a compreensão do modo como utilizam e modificam suas rotinas, como experimentam hipóteses de trabalho, como utilizam técnicas e instrumentos conhecidos e como recriam estratégias e inventam procedimentos e recursos.

Zeichner (1993) discute os termos "reflexão" e "investigação" pelos professores, tomando por base a idéia de que os professores não devem ser vistos apenas como meros aplicadores de conhecimentos produzidos na academia, mas sim como profissionais ativos na construção de sua ação profissional. Reconhece "a riqueza que reside na prática dos bons professores" (1993, p. 17) e no processo de reflexão sobre a própria prática como uma excelente fonte para a construção dos conhecimentos profissionais. Para o autor, quem não reflete, outorga a outros a solução dos próprios problemas.

Schön (1992) apresenta os conceitos de reflexão de maneira mais detalhada, classificando o processo como: reflexão na ação, reflexão sobre a ação e, mais tarde, a reflexão sobre a reflexão na ação. É um dos autores que mais investe na idéia de reflexão no processo de formação de professores. A proposta do conceito de "reflexão na ação" caracteriza os professores como profissionais capazes de aprender por meio da análise e interpretação da própria atividade.

Segundo Perez Gómez (1992, p. 104)

[...] com todas as dificuldades e limitações, a reflexão-na-ação é um processo de extraordinária riqueza na formação do profissional prático. Pode considerar-se o primeiro espaço de confrontação empírica com a realidade problemática, a partir de um conjunto de esquemas teóricos e de convicções implícitas do profissional. Quando o profissional se revela flexível e aberto ao cenário complexo de interações da prática, a reflexão na ação é o melhor instrumento de aprendizagem. No contato com a situação prática, não só se adquirem e constroem novas técnicas, esquemas e conceitos, como se aprende o próprio processo dialético da aprendizagem .

Para André (2002), as linhas de pesquisas sobre formação desenvolvidas em diferentes países apresentam, como diretriz, o reconhecimento da importância dos saberes docentes e da reflexão para o desenvolvimento e construção do conhecimento profissional, além de reconhecerem também o professor como sujeito ativo deste processo. As "competências" do professor estariam diretamente associadas às suas capacidades de reflexão, crítica, revisão e objetivação de sua própria prática e que responderiam por suas decisões pedagógicas. O profissional docente seria então um indivíduo capaz de argumentar e deliberar sobre suas próprias práticas. 
Voltamo-nos para as idéias apresentadas por Barth (1996), que buscou explorar e associar o sentido dos saberes docentes aos dos aprendizes durante o processo educativo, ou seja, aos saberes em ação. Para a autora, o princípio do trabalho docente reside no processo de "transmissão" do saber, mas de forma a favorecer a construção pessoal do aluno.

Em suas palavras,

[...] para poder utilizar os seus conhecimentos mais tarde, o aluno deve ele próprio construir o seu saber, mobilizando as ferramentas intelectuais de que dispõe e que podem ser aperfeiçoadas. Reproduzir um saber não é a mesma coisa que construí-lo. Nesta óptica a responsabilidade do professor é transmitir o saber de tal modo que esta construção pessoal seja possível. (BARTH, 1996, p. 22-3)

Coloca-se, assim, a reflexão, o pensamento e a inteligência a serviço da aquisição de conhecimentos, mostrando que o modo ou maneira "como" aprendemos torna-se tão importante quanto o "que" aprendemos. Apresenta-se a idéia de que o saber é indissociável do processo de aprendizagem. A formação de professores toma então tanta importância quanto a formação dos alunos. Deste modo, os processos formativos devem proporcionar ao professor a "oportunidade, através de um dispositivo coerente, de fazer experiência de um modo de abordar a aprendizagem durante sua própria formação", preparando a possibilidade de transferência a posteriori.

É interessante notar que, para Barth (1996), o saber em movimento, ou seja, a serviço do professor e do aluno é que deve ser objeto de estudo e aprofundamento. A autora encaminha para suas reflexões e experiências a fim de captar as características destes saberes em situações de vida profissional e cotidiana, caracterizando o saber como 'estruturado', 'evolutivo', 'cultural', 'contextualizado' e 'afetivo'. Ao mesmo tempo em que apresenta esta classificação, afirma que não pretende esgotar os aspectos relacionados à natureza do saber, deixando esta questão em aberto.

Para finalizar, Barth (1996) chama-nos a atenção para o fato de estarmos focalizando continuamente nossos estudos nos saberes construídos em detrimento do saber em construção. Nestes estudos, a visão predominante está associada ao conjunto de saberes ou conhecimentos constituídos.

[...] parecemos esquecer o outro lado do saber, o lado escondido: aquele que está a estruturar-se no cérebro dos alunos, aquele que evolui, aquele que é relativo ao tempo, ao contexto, à afetividade, aquele que é provisório e que precisa de mediação de outrem para se tornar um saber validado: o saber em construção. (BARTH, 1996, p. 87, grifos da autora)

Podemos, então, prever a necessidade de se formar o professor para que conheça não apenas sua própria maneira de relacionar-se com o saber (metaconhecimento), mas para utilizar este conhecimento em benefício da aprendizagem dos alunos. Se ao reconhecer e utilizar estratégias metacognitivas o indivíduo passa a monitorar sua própria aprendizagem (ZULIANI, 2000), por que não desenvolver estratégias deste tipo em professores em formação a fim 
de melhorar sua relação individual com o conhecimento e possibilitar ao professor a construção de atividades de ensino capazes de produzirem efeitos semelhantes nos alunos?

A independência na condução do próprio trabalho é conseguida quando o indivíduo está seguro sobre sua capacidade. Trata-se também de uma das habilidades mais requisitadas hoje pelo mercado de trabalho. Cabe à escola o desenvolvimento das habilidades necessárias para a vida em sociedade, sendo então sua função facilitar o desenvolvimento delas. O desenvolvimento da Ciência, por sua vez, apresenta uma inumerável quantidade de fenômenos agregados às suas explicações e, portanto, é preciso, necessariamente, fazer escolhas, tomar decisões. Quando o aprendiz passa a tomar decisões e controlar as variáveis numa atividade de aprendizagem, suas possibilidades de assumir o controle crescem muito.

Ao conhecer-se como aprendiz, ao refletir sobre a própria maneira de aprender, ao estabelecer um diálogo consciente com a própria aprendizagem, o professor estará fazendo com que se desenvolvam gradativamente o conhecimento sobre si próprio e, consequentemente, terá oportunidade de fazer o mesmo com seus alunos.

Como formar um professor metacognitivo? Parece-nos que não há receitas definitivas e que as possíveis respostas divergem de pesquisador para pesquisador. É importante, entretanto, levar em consideração o processo de construção dos saberes docentes. Os alunos devem ser convidados a resolver situações práticas análogas às que possivelmente encontrarão no seu dia-a-dia enquanto professores. Na medida em que o professor atua consciente de suas competências e limitações, avaliando continuamente sua ação docente, tanto mais será capaz de compreender sua atuação e ensinar metacognitivamente, ou seja, desenvolvendo em si próprio e nos alunos estratégias de regulação e controle da própria aprendizagem.

No Ensino de Química, esta necessidade se torna ainda maior, em virtude das deficiências já diagnosticadas (ZULIANI, 2000). Tomou-se a formação inicial como objeto de pesquisa com base nas proposições de Tardif (2000), para quem esta formação deve lançar mão do resgate da ação docente, da análise e reflexão sobre esta prática, e na proposição de alternativas que, por sua relevância, tornem-se significativas e passem a fazer parte do saber docente. Isto significa reconhecer a competência dos professores para controlar a própria formação. A metodologia investigativa utilizada na proposta de trabalho da disciplina, com o consequente desenvolvimento de estratégias metacognitivas, podem ser caminhos interessantes tanto para a capacitação de professores em exercício como para a formação inicial, uma vez que congregam estas importantes considerações e permitem, aos sujeitos, assumirem plena responsabilidade e controle pelo processo de aprendizagem.

\section{O que buscar no processo de formação: questão e objetivos da pesquisa}

Decidiu-se por buscar a compreensão das relações entre as vivências formativas proporcionadas aos sujeitos e suas interpretações sobre este fenômeno formativo. Justifica-se este interesse no fato expresso por Espitia (2000, p. 3), que afirma:

[...] A pessoa é um ser auto interpretativo. Os seres humanos são seres auto interpretativos, mas não de uma forma teórica. O são, porque as coisas têm importância para elas. Quando os seres humanos expressam e 
atuam em relação ao que estão comprometidos ou lhes interessam, tomam uma atitude. Os interesses ou inquietudes da pessoa ilustram o que é importante ou preocupante numa situação específica.

Se pudermos captar as expressões associadas às relações entre a vivência proporcionada ao indivíduo em um processo formativo que pretenda favorecer reflexão sobre a aprendizagem da docência e sua prática, estaremos nos encaminhando à questão de pesquisa aqui proposta, que pode ser formulada, desdobrando-se da seguinte maneira:

"Como um professor em formação, submetido a uma proposta formativa com base na metodologia investigativa, percebe sua aprendizagem?"

"De que maneira estes sujeitos expressam esta experiência relacionando-a ao processo formativo vivenciado e a outros contextos?"

Trata-se de buscar o ato pelo qual a pessoa apreende imediatamente o conhecimento de alguma coisa com que se depara (CHAUÍ, 2000), ou seja, buscar a leitura elaborada individual ou coletivamente pelos sujeitos a respeito do fenômeno vivenciado. Portanto, recorreremos a um estudo fenomenológico das percepções expressas nas observações verbais e escritas dos indivíduos.

\section{Metodologia aplicada: alguns conceitos necessários à análise dos dados - a semiótica social}

Com base nas questões de pesquisa que orientaram este trabalho, encontramos na semiótica social algumas possibilidades de respostas. Algumas perguntas apresentadas por Halliday (1998), em seu livro "A linguagem como semiótica social", parecem vir ao encontro daquelas aqui propostas. Entre elas, as duas primeiras apresentam especial interesse:

Como as pessoas decodificam as experiências sumamente condensadas da fala cotidiana e como utilizam o sistema social para fazê-lo?

$[\ldots]$

Como as pessoas revelam o ambiente ideacional e interpessoal no qual se deve interpretar o que estão dizendo? Em outras palavras, como se constrói o contexto social em que se produz o significado? (HALLIDAY, 1998, p. 143)

Para responder a estas questões, Halliday apresenta os constituintes elementares da teoria semiótica social da linguagem. O primeiro destes elementos, e que para nossos propósitos é muito importante, é o texto. Texto é tudo o que dizemos ou escrevemos, pode ser considerado como o registro das ações sociais (LEMKE, 1996) e representa tanto os eventos reais como os resultados produzidos por eles. O texto é, portanto, uma unidade semântica, pois, "a linguagem pode expressar efetivamente significados ideacionais e interpessoais só porque pode criar texto. O texto é a linguagem em operação e o componente textual inclusive os sistemas semânticos pelos quais se cria o texto" (HALLIDAY, 1998, p. 172). 
Associado a um contexto de situação, pode ser caracterizado como contexto social ou, ainda, do ponto de vista da sociolinguística, corresponde ao leque de opções características de uma situação específica, ou seja, "estruturas semióticas" que são um conjunto de significados derivados do sistema semiótico cultural e podem ser representadas a partir de três dimensões: o campo, que é caracterizado pela ação social e sua manifestação mais importante, que é o assunto; o teor se constitui nas relações entre os participantes, e o modo, que é o canal escolhido para a comunicação e é aqui que a linguagem assume o papel de meio.

Para Halliday (1998), estas três dimensões são essencialmente "uma estrutura conceitual para representar o contexto social como ambiente semiótico no qual as pessoas trocam significados (p.145)". Ao compreendermos as propriedades semióticas do contexto a partir destas três dimensões, podem-se fazer predições sobre as propriedades semânticas de um texto. Isto é possível a partir do "registro". Para que não o caracterizemos por suas funções lexicogramaticais, Halliday define registro em termos semânticos: "Um registro pode definirse como configuração de recursos semânticos que os membros de uma cultura associam tipicamente a um tipo de situação, é o potencial de significado razoável em um contexto social dado" (p. 146).

Os componentes funcionais do sistema semântico são vistos como maneiras de significação da linguagem em todos os contextos sociais e estão classificados em três funções: a função ideacional, que está relacionada ao conteúdo, ou seja, a codificação da experiência individual vivenciada; a função interpessoal, que representa a ação do indivíduo sobre o ambiente e sobre os outros participantes, e, por fim, a componente textual, relacionada ao texto. Esta componente está associada ao modo pelo qual as outras duas se expressam e apresenta, portanto, uma função habilitadora.

Na perspectiva sociolinguística da semântica proposta por Halliday, os principais componentes do sistema sociolinguístico vinculam-se entre si, formando uma rede de relações que focalizam sua atenção nos processos de interação humana. Metodologicamente, os dados se constituem em fatos observados a partir do "texto em situação", onde se parte do que as pessoas dizem na vida real. A interpretação desses dados reais deve estar vinculada ao sistema linguístico e ao contexto social.

Nesta perspectiva, Lemke (1996) conceitua a semiótica social como a teoria que procura explicar como os indivíduos elaboram significados a partir do grupo social ao qual estão inseridos. Se os significados são construídos no grupo social e expressos por meio da linguagem oral ou escrita, parece possível utilizar a fenomenologia como método de interpretação de dados, pois esta tem grande aplicação nos fenômenos situados da vida diária, sobretudo aqueles que podem ser descritos por meio da linguagem (MARTINS e BICUDO, 1994).

Portanto, os dados em uma pesquisa constituem-se a partir dos fatos observados do texto em situação, buscando elucidar o que as pessoas dizem. Para Halliday (1998), qualquer orientação metodológica, que pretenda utilizar os recursos da semiótica social, precisa transcender a limitação e interpretar a linguagem, não como um conjunto de regras, mas como um recurso para se obterem os significados presentes no texto.

Para descrever a ação social, usando a semiótica, lançamos mão de um sistema de recursos semióticos. "Uma formação semiótica é um padrão concreto de ação significativa que usa recursos semióticos e que se executa e identifica repetidamente dentro de uma comunidade" (LEMKE, 1996, p. 205). 
Este conjunto de recursos, que se caracterizam por sua funcionalidade, permite que elaboremos significados e representações. Parece-nos que, normalmente, as ações não acontecem isoladas, mas formando sequências. A estas sequências, Lemke (1996) chama de estruturas de atividades. Para o propósito desta análise, são estas estruturas que se fazem importantes, pois, para o autor, elas têm elementos constituintes com tipos de ações específicas e definidas funcionalmente e, por isto, estabelecem relações específicas com outras estruturas.

Quando participamos de uma atividade, relacionamos palavras e eventos em padrões familiares relacionados ao mesmo texto ou a diferentes textos que mantenham relações familiares ou de significado. A esta possibilidade, ele chama de intertextualidade e, aos textos empregados para dar sentido ao texto em questão, de intertextos. As conexões intertextos são muito importantes para que os membros de uma comunidade elaborem significados que não se podiam elaborar a partir de um único evento.

Lemke afirma ainda que a análise semiótica não deve ser vista como uma "camisa de força", concordando com Halliday (1998) em relação à importância do sistema em detrimento da estrutura. Em suas palavras: “A análise semiótica não é uma 'camisa de força', é uma expressão sistemática de como criamos sentido dos textos e eventos, incluindo as ambigüidades e os múltiplos significados que encontramos" (LEMKE, 1996, p. 217).

Estas reflexões remetem-nos às características da pesquisa fenomenológica. O "fenômeno" na pesquisa qualitativa é caracterizado como um evento situado socialmente e que só se desvela a partir da representação elaborada pelos sujeitos por meio da verbalização dos significados.

O método fenomenológico aplicado à pesquisa (MARTINS e BICUDO, 1994) parte das descrições dos sujeitos, e destas descrições o pesquisador, fazendo uso das análises ideográfica e nomotética (ZULIANI, 2006), deve buscar as essências do fenômeno estudado. Como na semiótica social, procuram-se as essências ou estruturas de um fenômeno dependente de um contexto socialmente situado, distancia-se das generalizações buscadas pela pesquisa quantitativa. Portanto, nesta pesquisa, optou-se por um estudo Fenomenológico com base na Semiótica Social.

\section{Como se coletaram os dados}

Como já vimos na metodologia proposta para a pesquisa (estudo do fenômeno), o objetivo principal foi o de buscar, nas descrições dos sujeitos, sua percepção sobre o processo de aprendizagem da docência vivenciado por eles. Além disto, identificar as relações estabelecidas por eles entre a própria aprendizagem e sua influência no processo de ensino e aprendizagem de Química.

Feita a opção pela pesquisa qualitativa com enfoque fenomenológico, a entrevista e as avaliações escritas foram os instrumentos de coleta de dados utilizados neste trabalho. Foram realizadas duas entrevistas (E1, E2), uma no início da disciplina e outra ao final, ambas gravadas em áudio, além de duas avaliações reflexivas escritas (A1, A2). As questões utilizadas nas entrevistas semiestruturadas e nas avaliações são disponibilizadas no apêndice deste texto.

As entrevistas foram feitas em grupo, utilizando-se um protocolo com questões semiestruturadas com a finalidade de se ouvirem vários sujeitos ao mesmo tempo, garantindo acesso a dados muitas vezes não disponibilizados numa entrevista individual. Apesar das van- 
A influência dos processos que buscam ...

tagens da entrevista grupal, entre elas o questionamento mais aprofundado dos membros do grupo, a coleta de dados menos onerosa e a estimulação dos entrevistados. Fontana e Frey (1994) advertem para alguns problemas possíveis de serem defrontados. Entre estes problemas, os autores citam que a cultura emergente no grupo pode interferir na expressão individual, ou mesmo o grupo ser dominado pelas idéias de um dos indivíduos.

Os autores alertam que o pesquisador deve estar preparado para estas eventualidades, usando sua habilidade e procurando interferir o mínimo possível na dinâmica interna do grupo. Como já havíamos passado por uma experiência deste tipo em trabalho anterior e os resultados haviam sido satisfatórios (ZULIANI, 2000), optamos por utilizar novamente esta técnica de entrevista.

\section{Os sujeitos da pesquisa}

A pesquisa foi desenvolvida com 25 alunos das disciplinas Prática de Ensino de Química I e II de uma Universidade Federal durante o ano letivo de 2002 (no segundo semestre de 2002 e primeiro semestre de 2003 em virtude de calendário especial pós-greve). O trabalho foi iniciado com todos os alunos da disciplina, utilizando como princípio norteador a importância da inserção destes alunos em situações de vivência prática da docência e de reflexão sobre os pressupostos vigentes para a elaboração de atividades de ensino, capazes de produzir aprendizagens que se tornassem eficazes.

Nesta perspectiva, os alunos da Prática de Ensino de Química foram convidados a partir de reflexões, leituras e discussões de textos em grupo e, em sala de aula, elaborar uma atividade de ensino com base na proposta investigativa (ZULIANI, 2000), vivenciando a própria proposta mesmo antes de obterem detalhes sobre a mesma. Dos vinte e cinco alunos que iniciaram a disciplina, doze foram selecionados para a análise dos dados, justificando-se esta escolha nas seguintes proposições:

1 Foram os alunos que responderam as duas entrevistas, inicial e final. Embora todos os alunos tenham sido entrevistados inicialmente, somente se levou a termo a entrevista final com os alunos que efetivamente completaram o processo, ou seja, além de frequentarem as aulas da disciplina e apresentarem os trabalhos planejados, estes alunos afetivamente ministraram os minicursos aos alunos do Ensino Médio.

2 Além de responderem às entrevistas e apresentarem os minicursos, foram os alunos que responderam à maioria das avaliações propostas.

3 Por termos optado por uma metodologia de pesquisa com base na fenomenologia, o tamanho da amostra deve ser levado em consideração. Apesar de ser difícil descrever a estrutura do fenômeno com base em um único sujeito, como comentado por Moreira (2002) em relação ao método fenomenológico proposto por Giorgi (1985 apud MOREIRA, 2002), nem sempre uma grande amostra será responsável por um maior número de informações.

Apesar de termos a autorização de todos os alunos para participarem da pesquisa proposta, eles foram identificados por um conjunto de duas letras aleatórias, apresentadas no Quadro 1, que faziam parte de seu nome, a fim de que se resguardasse seu nome verdadeiro. As atividades propostas para o grupo de alunos matriculados nas duas disciplinas foram desenvolvidas por todos os alunos, com exceção da aplicação dos minicursos, que foram prejudicados pela reforma dos laboratórios do Centro de Divulgação Cientifica e Cultural, USP/ São Carlos (CDCC) e, portanto, não foram prejudicados nos objetivos e conteúdos propostos 
para ambas as disciplinas. Apesar de não aplicarem os minicursos, estes alunos elaboraram seus projetos, os quais foram discutidos em sala de aula e testados por eles nos laboratórios da Universidade.

\section{Análise ideográfica}

A análise ideográfica tem como objetivo elucidar a ideologia que permeia as descrições dos sujeitos (MARTINS e BICUDO, 1994) e refere-se às idéias presentes nas descrições. Para realizá-la, é necessária a leitura de cada descrição individual a fim de se encontrarem e isolarem as unidades de significado para a análise psicológica. A tradução desta análise se dá por meio de uma descrição pormenorizada das expressões cotidianas do sujeito na linguagem do pesquisador, buscando chegar às categorias de análise com base nas expressões do sujeito. Segundo Martins e Bicudo (1994, p. 100), o objetivo é "chegar a categorias, passando por expressões concretas e não chegar a elas por meio de abstrações ou de formalizações que são seletivas de acordo com o critério adotado".

Trata-se, portanto, de 'descrever o descrito', no que, segundo Rezende (1990), consiste a essência do método fenomenológico. Para ele,

[...] o método fenomenológico é discursivo e não apenas definitivo das essências. $\mathrm{Na}$ verdade, a intuição das essências, visada pela fenomenologia, não diz respeito a um mero conteúdo conceitual que possa ser definido, mas à significação de uma essência existencial, que como tal deve ser descrita. (REZENDE, 1990, p. 17)

Daí a importância desta fase da análise de dados. Apesar disso, para o leitor, interessado nos resultados da pesquisa, a leitura desta tradução de linguagem coloquial para a psicológica pode se tornar difícil, pois ela acaba parecendo repetitiva (ZULIANI, 2006). Após a coleta dos dados, já descrita anteriormente, foram estabelecidas as unidades de $\operatorname{significado}^{3}$ nas quais se têm representados os dados obtidos nas entrevistas iniciais, nas entrevistas finais e nas avaliações escritas individuais com os diferentes grupos.

O processo de coleta de dados empreendidos nesta pesquisa procurou recolher estas atribuições em diferentes momentos, não para que se estabeleçam comparações entre estado final e inicial de um processo, mas com base na crença de que as concepções de cada indivíduo se mostram de maneira construtiva e evolutiva.

No Quadro 1 apresentamos parte de duas unidades de significado extraídas da primeira entrevista com os licenciandos: Como eu aprendo e relação entre a própria aprendizagem e dos alunos.

\footnotetext{
${ }^{3}$ Unidades de significado: são discriminações espontaneamente percebidas nas descrições dos sujeitos, segundo atitude, disposição e perspectiva do pesquisador e sempre focalizando o fenômeno que está sendo estudado (MARTINS e BICUDO, 1994).
} 
A influência dos processos que buscam ...

Quadro 1. Unidades de significado retiradas da entrevista 1.

\begin{tabular}{|c|c|c|c|}
\hline Unidades de & & Linha & Descrição \\
\hline \multirow{10}{*}{$\begin{array}{l}\text { Como eu } \\
\text { aprendo }\end{array}$} & \multirow[t]{3}{*}{ Não sei } & 556 & Ju: Eu não sei.... \\
\hline & & $562-566$ & $\begin{array}{l}\text { Ju: eu tenho que ler, entender o que eu estou } \\
\text { lendo... se não eu procuro... alguém pra me } \\
\text { explicar... normalmente eu } \\
\text { não entendo na } 1^{\text {a }} . . \text { eu não sei... eu tento fazer } \\
\text { um resumo... um negócio assim... pra eu ter... } \\
\text {...que eu estou fazendo, mas não sei te falar } \\
\text { direito não... }\end{array}$ \\
\hline & & 578 & $\begin{array}{l}\text { Ju: Eu me desespero...(se tiver que aprender } \\
\text { algo rapidamente) }\end{array}$ \\
\hline & \multirow[t]{3}{*}{$\begin{array}{l}\text { Com } \\
\text { pesquisa } \\
\text { e leitura }\end{array}$} & $568-570$ & $\begin{array}{l}\text { Le: Eu acho que a gente tem que procurar mais } \\
\text { informações... estar se atualizando... lendo } \\
\text { bastante, a respeito não só da Química, mas de } \\
\text { outras.... }\end{array}$ \\
\hline & & $579-580$ & $\begin{array}{l}\text { Le: Vou a base do café e começo a ler... e só } \\
\text { vou dormir a hora que eu conseguir realmente... } \\
\text { pelo menos absorver um pouquinho... }\end{array}$ \\
\hline & & $581-582$ & $\begin{array}{l}\text { Li: Eu também na base de leitura e da leitura... } \\
\text { eu tenho que pegar o material sobre aquele } \\
\text { assunto e ler de preferência sozinha... }\end{array}$ \\
\hline & \multirow[t]{2}{*}{ Persistindo } & $579-580$ & $\begin{array}{l}\text { Le: Vou a base do café e começo a ler... e só } \\
\text { vou dormir a hora que eu conseguir realmente... } \\
\text { pelo menos absorver um pouquinho... }\end{array}$ \\
\hline & & $581-582$ & $\begin{array}{l}\text { Li: Eu também na base de leitura e da leitura... } \\
\text { eu tenho que pegar o material sobre aquele } \\
\text { assunto e ler de preferência sozinha... }\end{array}$ \\
\hline & Motivação & $573-576$ & $\begin{array}{l}\text { Le: Bem... depende também... a motivação, } \\
\text { como eu estou nesse dia... que às vezes eu } \\
\text { estou atarefado de coisas pra fazer e aí chega a } \\
\text { noite... que é o tempo que eu tenho disponível... } \\
\text { acabo chegando cansado e não tenho } \\
\text { motivação nenhuma... }\end{array}$ \\
\hline & $\begin{array}{l}\text { Indicar } \\
\text { pesquisa e } \\
\text { leitura }\end{array}$ & $591-601$ & $\begin{array}{l}\text { Li: eu nunca dei aula assim... mas eu acho que } \\
\text { seria fundamental passar um resumo... uma } \\
\text { coisa assim... pro aluno... eu penso isso... fazer } \\
\text { um resumo da aula ou cópia de um livro... se } \\
\text { não tiver um livro didático... Alguma coisa, além } \\
\text { do que copiou... porque tem gente que copia } \\
\text { muito assim...mal... não copia tudo... copia por } \\
\text { partes... }\end{array}$ \\
\hline
\end{tabular}


Zuliani, S. R. Q. A.; Hartwig, D. R.

Quadro 1. continuação

\begin{tabular}{|c|c|c|c|}
\hline $\begin{array}{l}\text { Unidades de } \\
\text { significado }\end{array}$ & & Linha & Descrição \\
\hline \multirow{6}{*}{$\begin{array}{l}\text { Relação } \\
\text { entre a } \\
\text { própria } \\
\text { aprendizagem } \\
\text { e a do aluno }\end{array}$} & \multirow[t]{3}{*}{$\begin{array}{l}\text { Indicar } \\
\text { pesquisa e } \\
\text { leitura }\end{array}$} & $609-610$ & $\begin{array}{l}\text { Li: Ah..! então eu passaria um resumo da aula ou } \\
\text { indicaria onde o aluno conseguia obter mais } \\
\text { informações, estimularia... sei lá, pesquisa na } \\
\text { internet esse tipo de coisas... }\end{array}$ \\
\hline & & 603 & Li: porque a leitura é fundamental... \\
\hline & & 604-608 & $\begin{array}{l}\text { Ki: Eu também concordo com a Li, você falou da } \\
\text { internet, não tinha passado pela minha cabeça... } \\
\text { na época que a gente tava, não tinha..., a gente } \\
\text { não tinha acesso a internet tão fácil igual tem } \\
\text { hoje..., na internet você acha de tudo mesmo... } \\
\text { duro é convencer o pessoal a procurar o que } \\
\text { interessa... }\end{array}$ \\
\hline & \multirow{2}{*}{$\begin{array}{l}\text { Ensinar a } \\
\text { procurar e } \\
\text { selecionar a } \\
\text { informação }\end{array}$} & $609-610$ & $\begin{array}{l}\text { Li: Eu acho que a dificuldade é que o aluno do } 2^{\circ} \\
\text { grau, não sabe distinguir o que é útil, selecionar o } \\
\text { que realmente interessa... }\end{array}$ \\
\hline & & $11-615$ & $\begin{array}{l}\text { Ju: Oh! Eu até hoje eu tenho grande dificuldade } \\
\text { de saber aonde eu encontro as coisas, onde } \\
\text { procurar, o que procurar... eu preciso de alguém } \\
\text { falando, oh!, faz isso, faz aquilo..., sabe, eu tenho } \\
\text { muita dificuldade de eu mesma me organizar, pra } \\
\text { falar, não... eu vou começar aqui... }\end{array}$ \\
\hline & $\begin{array}{l}\text { Analisar as } \\
\text { dificuldades } \\
\text { e provocar a } \\
\text { participação }\end{array}$ & $618-631$ & $\begin{array}{l}\text { Le.. ... ... às vezes a gente aprende daquele jeito, } \\
\text { eu acho que a gente tem que ser livre... pra } \\
\text { preparar do jeito que a gente achar melhor... de } \\
\text { procurar estratégias, pra poder dar uma boa } \\
\text { aula... pra pelo menos assim... a turma, né... estar } \\
\text { acompanhando a aula... não tá brincando... } \\
\text { porque o exemplo que tive, foi quando comecei } \\
\text { dar aula mesmo, né... no comecinho... o pessoal } \\
\text { não respeitava, e agora tendo uma aula mais do } \\
\text { cotidiano, eles estão prestando atenção... às } \\
\text { vezes eu faço jogos na sala de aula, ai eu brinco, } \\
\text { levo os alunos lá pra frente... aí ensinava alguns } \\
\text { conceitos de eletronegatividade, fazendo com que } \\
\text { o pessoal seja... participe sendo, núcleo, elétron... } \\
\text { eles gostam, eles participam... aí a aula fica bem } \\
\text { mais dinâmica... então eu acho assim, que a } \\
\text { gente não pode se prender... às vezes é ao que a } \\
\text { gente aprende aqui... a gente tem que tentar } \\
\text { mudar alguma coisa... }\end{array}$ \\
\hline
\end{tabular}

Análise nomotética: convergências nas compreensões dos sujeitos de pesquisa

A análise nomotética tem por objetivos identificar pontos convergentes e divergentes nas descrições individuais. Refere-se à normatização ou estabelecimento de generalizações advindas do tratamento dos dados. Para a pesquisa qualitativa, entretanto, é praticamente im- 
possível realizá-la sem passar pela análise ideográfica, pois é durante esta análise que se estabelecem as unidades de significado.

Segundo Martins e Bicudo (1994), a estrutura psicológica geral é resultante da compreensão das convergências e divergências que se mostram nos casos individuais. Entretanto, é muito importante ressaltar que o que determina a estrutura psicológica geral é sua importância ou centralidade para a questão formulada na pesquisa, e não sua frequência. Chega-se então aos conjuntos de essências que caracterizam a estrutura do fenômeno.

Levando em consideração o fato de utilizarmos o trabalho em grupo em todas as fases da pesquisa, optamos por realizar as análises também nos grupos. Para buscar então a essência do fenômeno pesquisado, se fará esta passagem do individual para o geral por meio do discurso dos diferentes grupos quando submetidos a cada um dos instrumentos de coleta de dados, onde buscar-se-á formular de maneira mais clara as essências observadas.

\section{Resultados e discussão}

Todos os textos obtidos de cada um destes eventos foram descritos na análise ideográfica na qual se indicaram as respectivas unidades de significado, representativas das idéias dos sujeitos em relação a cada um destes eventos (ZULIANI, 2006). Em seguida, passando-se do individual para o geral, buscaram-se as convergências e divergências nos textos ${ }^{4}$ produzidos pelos sujeitos em cada evento, com a finalidade de compreensão dos significados atribuídos. Esta segunda parte caracteriza a análise nomotética. As duas análises empreendidas, embora tenham possibilitado compreender vários aspectos das relações dos sujeitos com o processo vivenciado durante a formação, não respondiam separadamente a principal questão na qual se fundamentou esta pesquisa:

"De que maneira os sujeitos percebem e expressam sua aprendizagem pessoal e sua transferência a outros contextos a partir do evento proposto (processo formativo vivenciado)?"

Em cada texto constituído (HALLIDAY, 1998) com base nos diferentes eventos, emergem formações semióticas que se repetem nos demais, fazendo com que percebêssemos a existência de uma importante característica intertextual entre eles. As respostas a questionamentos diversos, propostos aos sujeitos de pesquisa nos diferentes instrumentos utilizados na coleta de dados, indicavam a construção de uma mesma representação semântica pelos sujeitos.

O olhar mais demorado para as convergências e divergências estabelecidas na análise nomotética tornaram evidentes as compreensões e representações dos sujeitos em relação à sua aprendizagem e à aprendizagem da docência. Evidenciando textualmente estas representações de maneiras diversas, a maioria das formações semióticas determina sempre um mesmo padrão temático que nomeamos de "Percepção e expressão da aprendizagem pessoal". Den-

${ }^{4}$ Texto utilizado aqui na concepção de Halliday (1998). 
tro deste padrão temático, os sujeitos de pesquisa classificam as estruturas em dois grandes grupos:

1 Buscar conhecimento e autoaprendizagem.

2 Relação aprendizagem pessoal e a dos alunos.

Estas estruturas semióticas são representadas em número de vezes enunciadas pelos sujeitos (número entre parênteses apresentado ao lado do respectivo sujeito) e por instrumento no Quadro 2, a partir do texto produzido pelos sujeitos (HALLIDAY, 1998). A questão de pesquisa proposta centra-se na percepção da aprendizagem pessoal, portanto, as estruturas semióticas detectadas apresentam relação direta com a mesma e serão tomadas para análise e discussão.

Neste trabalho discutiremos os resultados referentes apenas à estrutura: "Buscar conhecimento e autoaprendizagem", pois o espaço necessário à discussão de todos os resultados ultrapassariam o destinado a este artigo.

Quadro 2. Estruturas semióticas.

\begin{tabular}{|c|c|c|c|}
\hline \multirow{7}{*}{$\begin{array}{l}\text { Percepção } \\
\text { e expressão } \\
\text { da } \\
\text { aprendizagem } \\
\text { pessoal }\end{array}$} & \multicolumn{2}{|c|}{ Buscar conhecimento - autoaprendizagem } & $\begin{array}{l}\text { A1: Le (6); Ki (2); Po (2); Ju; Ar; Ne } \\
\text { A2: Po (2); Ma; Ki; Li; Le; Ju } \\
\text { E1: Ma (2); Pa (2); Li(2); Fa; Ar; Po; } \\
\text { Roe; Ju } \\
\text { E2: Li (5); Ju (4); Le (3); Ma(5); Po (2) }\end{array}$ \\
\hline & \multirow{6}{*}{$\begin{array}{l}\text { Relação } \\
\text { entre a } \\
\text { aprendizagem } \\
\text { pessoal } \\
\text { e a dos alunos }\end{array}$} & Indicar e ensinar a pesquisar & $\begin{array}{l}\text { E1: Li; Ki; Ju (3)e Le } \\
\text { A2: Le, Li, Ju, Ma e Po }\end{array}$ \\
\hline & & Não sei & E1: Ju \\
\hline & & $\begin{array}{l}\text { Conhecer dificuldades } \\
\text { dos alunos }\end{array}$ & $\begin{array}{l}\text { E1: } \mathrm{Le} \\
\text { A1: } \mathrm{Ne} \\
\text { A2: } \mathrm{Fa}\end{array}$ \\
\hline & & Aprender com os alunos & $\begin{array}{l}\text { A1: Le } \\
\text { E2: Ma }\end{array}$ \\
\hline & & Minhas próprias dificuldades & E2: Li \\
\hline & & $\begin{array}{l}\text { Nem sempre minhas estratégias } \\
\text { são válidas }\end{array}$ & E2: Ki \\
\hline
\end{tabular}

\section{Buscar conhecimento e autoaprendizagem}

Quais são as relações entre conhecimento e aprendizagem? Da mesma maneira que são inúmeros os conceitos de conhecimento, também ocorre com os de aprendizagem. Vários autores têm proposto teorias de aprendizagem que se iniciaram nas teorias condutivistas até chegarmos às teorias cognitivas e social cognitivas. Por outro lado, a aprendizagem pressupõe a conexão entre o que o indivíduo já conhecia anteriormente e os novos conhecimentos elaborados a partir deles. Ficaram explícitas, na linguagem cotidiana dos sujeitos (HALLIDAY, 1998), as idéias construídas ao longo do seu processo formativo e capturadas por meio dos instrumentos de coleta de dados. 
Se o indivíduo é capaz de construir conhecimentos a partir daqueles que já fazem parte de seu repertorio, seria capaz de buscar a autoaprendizagem? Barth (1996), citando Dewey, afirma que "aprender" significa aprender a pensar; para ela a compreensão pode ser vista como um "processo de conceptualização" no qual o processo está ligado ao produto, ou seja, não se pode separar o pensamento de seu conteúdo e ainda "daquilo de que dispõe o pensamento", ou o que o indivíduo já sabe e que garante a significação do novo conhecimento (BARTH, 1996, p. 204).

Em todas as respostas produzidas na Entrevista 1, os sujeitos associam a busca de conhecimentos à aprendizagem da docência como necessidade profissional e à necessidade de aprender. Isto parece coerente com as idéias apresentadas por Pozuelos (1997), para quem a formação deve levar em consideração as necessidades da prática profissional para a elaboração de atividades formativas, sejam elas iniciais ou aquelas propostas para os professores já em exercício. "A prática educativa em suas situações reais é a que gera e produz problemas que se precisam resolver e investigar" (POZUELOS, 1997, p. 287).

$\mathrm{Da}$ necessidade de aprender a ser professor, manifestada por estes alunos, $\mathrm{Pa}, \mathrm{Ar}$, e Ma indicam uma outra, que é a aquisição de novos conhecimentos. Eles associam este interesse à importância de aprender e de gostar de aprender. Lafortune e Saint-Pierre classificam a motivação como uma das dimensões afetivas do processo de construção do conhecimento e da aprendizagem. Para as autoras, "motivação é uma soma de desejo e de vontade que impele uma pessoa a realizar uma tarefa ou a visar um objetivo que corresponde a uma necessidade" (LAFORTUNE e SAINT-PIERRE, 2001, p. 35).

No caso destes alunos, a motivação parece ter sido desencadeada pelas experiências encorajadoras ou, mesmo, pela necessidade de buscar novas competências, o que nos leva a crer que esta busca de conhecimento está ligada ao desejo de aprender. Além disso, os alunos valorizam a aquisição de conhecimento como um investimento na evolução do próprio saber. Segundo as autoras, passamos por experiências deste tipo quando temos a sensação de que a tarefa a ser realizada tornou-se mais ou menos difícil.

Isto se torna possível quando refletimos sobre uma determinada estratégia de aprendizagem utilizada e somos capazes de avaliá-la criticamente. Esta gestão passa, segundo as autoras, por três atividades fundamentais: o planejamento, o controle e a regulação. Estas atividades foram oferecidas aos sujeitos desta pesquisa por intermédio da intervenção realizada e das aplicações dos minicursos, entrevistas e avaliações propostas. Parece-nos que a associação direta entre a percepção da aprendizagem pessoal e a idéia de buscar conhecimento e autoconhecimento, apresentada pelos alunos em todos os instrumentos de coleta de dados, confirma esta hipótese.

Ainda nesta mesma entrevista, eles associam o conhecimento à atualização do professor e a sua mobilização constante por aprender, ao seu sucesso em sala de aula. Para Porlan e Rivero (1998), os conhecimentos profissionais têm algumas características que devem ser levadas em consideração a fim de se elaborarem possíveis propostas de formação. Todas estas considerações evidenciam a necessidade da proposição de programas de formação que atendam a esta complexidade de maneira a proporcionar, aos futuros professores, uma formação capaz de desenvolver sua profissionalidade, mas que possibilitem também a construção individual de habilidades de autoaprendizagem. Conforme os dados obtidos, estes sujeitos entendem sua aprendizagem pessoal como uma necessidade de busca e aprendizagem profissional e, portanto, suas crenças incluem a necessidade de mobilização para aprender. 
$\mathrm{Na}$ Avaliação 1, o segundo instrumento de coleta de dados utilizado, novamente se expressam, nas propostas dos sujeitos: a necessidade de buscar conhecimentos, autoaprendizagem, além de autonomia e responsabilidade por esta aprendizagem.

Alguns atribuem a busca de conhecimento à necessidade de aprender a ensinar. Segundo eles, este é o objetivo básico da proposta para a disciplina. Para um deles em especial, além de capacitá-los para a docência, por meio de uma metodologia diferenciada o curso os prepara para que eles próprios se tornem aprendizes eficientes. Um dos principais objetivos do ensino, senão o mais importante, é "tornar o saber acessível".

$\mathrm{Na}$ opinião de Barth (1996), é função do professor, enquanto mediador, favorecer a aquisição do conhecimento pelo educando, não como mera aquisição do conhecimento estabelecido, mas como construção compartilhada. Estes alunos demonstram, em sua reflexão, a valorização de uma estratégia que pode ser usada tanto pelo aluno como pelo professor, assim ambos estarão em processo de aprendizagem conjunta. Barth (1996) indica claramente esta necessidade, afirmando que as definições devem se tornar ferramentas para o aprender e, para tanto, o professor deverá

[...] abandonar a idéia de transmissão de conhecimentos enquanto exposição descritiva, claramente estruturada por etapas logicamente ligadas e passar a vê-la como um processo de co-construção de sentido, procura em comum de significado que deve ser guiada e modelada. (BARTH, 1996, p. 138)

Alguns entendem que "aprender a aprender" foi, de fato, o objetivo mais importante proposto pela disciplina e que esta atitude está diretamente ligada à construção de competências profissionais. Mudamos facilmente nosso discurso em relação às questões pedagógicas mais urgentes como, por exemplo, "tornar o educando um ator autônomo na construção do seu saber", mas somos lentos para deixar de lado nossas crenças e alterar a ação. Apesar disso, um primeiro passo para as mudanças tem, por base, a consciência e reconhecimento de que elas são necessárias.

A percepção dos licenciandos parece ir ao encontro do que nos diz Perez Gómez em relação à construção do pensamento prático dos professores:

O pensamento prático do professor não pode ser ensinado, mas pode ser aprendido. Aprende-se fazendo e refletindo na/ e sobre a ação. Por meio da prática, é possível apoiar e desenvolver o pensamento prático, graças a uma ação conjunta (e recíproca) entre o aluno mestre e o professor ou tutor. (PEREZ GÓMEZ, 1992, p. 112, grifos do autor)

A autoaprendizagem, indicada pelos alunos como essencial no processo de formação, passa também pela atuação do formador. Barth (1996) e Perez Gómez (1992) concordam com a necessidade de se investir num processo de construção compartilhada de conhecimentos a fim de, progressivamente, favorecer a autonomia desta construção.

Em acréscimo a estas considerações, outros três alunos apresentam a idéia de que a autoaprendizagem só poderá ser favorecida a partir de um processo reflexivo de autoavaliação. 
Nas palavras de um deles, "todos os aspectos vistos serviram para uma melhor auto-avaliação e crescimento". Estas características parecem coerentes com as observações de Schön (1992) a respeito do trabalho de Eleanor Duckworth em um curso para professores na universidade de Harvard:

O curso que ela orienta [...] tem como objetivo fazer com que os professores tomem consciência de sua própria aprendizagem: como é que aprendem a compreender o sentido das fases da Lua, de bolas rolando por planos inclinados ou das coisas intrigantes que as crianças dizem e fazem nas salas de aula? (SCHÖN, 1992, p. 90)

Todos os alunos que nesta avaliação associam sua aprendizagem à busca pessoal, apesar de maneiras diversas, têm fortes crenças de que esta busca será capaz de fazê-los participar do processo de aprendizagem não como meros expectadores, mas como atores capazes de buscar seu conhecimento, participando da sua construção de maneira autônoma e responsável.

A Avaliação 2, realizada no final da Prática de Ensino II, vem indicar uma ratificação dos dados percebidos nos dois instrumentos anteriores. Parece que o trabalho, desenvolvido durante o tempo intermediário às duas avaliações, possibilitou a estes sujeitos uma reflexão mais centrada sobre o processo formativo, bem como em relação ao ensinar (alguns deles já haviam desenvolvido os minicursos com os alunos). A maioria dos alunos refere-se à autoaprendizagem, ao estudo e à atualização profissional como determinantes para uma prática de qualidade. Segundo um deles, é necessário que o professor seja capaz de investir na própria formação.

Este aluno pode ainda não demonstrar confiança em sua formação e conhecimentos para assumir a profissão, mas, ao mesmo tempo, apresenta a opinião preconcebida sobre a necessidade de formação como um autoinvestimento. Isto é referendado nos dizeres de Barth: “[...] ao consciencializarmo-nos dos critérios de avaliação - os que se referem ao saber e à apreensão desse saber - construimos um gráfico de análise do nosso próprio funcionamento do saber em construção" (BARTH, 1996, p. 205).

$\mathrm{O}$ aluno consegue perceber a utilidade dos conhecimentos adquiridos e a possibilidade de analisar e avaliar a construção de novas estratégias de aprendizagem. Por outro lado, um outro aluno acredita que, pelo fato de ser responsável pela construção de parte da Ciência, enquanto pesquisador (aluno de pós-graduação), tem um compromisso redobrado em relação à aplicação deste conhecimento pela sociedade e no ajudar os alunos na reflexão crítica sobre esta aplicação. Parece-nos que estas considerações confirmam o que Lemke (1996) propõe como a mais provável das causas para as dificuldades dos alunos ao aprenderem Ciência, "a matéria de estudo da Ciência está organizada para parecer como algo completamente alheio à experiência cotidiana dos alunos" (LEMKE, 1996, p. 167).

Além disso, a linguagem utilizada pode se tornar um obstáculo à compreensão e construção de significados. A Ciência nada mais é do que uma maneira de explicar o mundo físico e, por este motivo, permeia nosso dia-a-dia, e, embora tenha linguagens específicas, reflete o mundo a nossa volta. Para Lemke (1996), um dos maiores problemas gerados pelo Ensino da Ciência, em relação aos alunos, é permitir estas distorções. Em suas palavras: "É perigoso para a sociedade termos alunos que deixam a escola acreditando que a ciência é um caminho perfeito para o absoluto, para as verdades objetivas, descobertas por pessoas sobre-humanas" (LEMKE, 1996, p. 187). 
Na opinião deste aluno, assim como para Lemke, é necessário mostrar o lado humano da Ciência, que é uma atividade desenvolvida por pessoas reais, que cometem erros como todos nós, e que estão sujeitas a todas as dificuldades e acertos aos quais estamos também expostos.

No último dos instrumentos utilizados, a entrevista final, verifica-se novamente, em todos os sujeitos, a percepção de aprendizagem como algo que deve ser construído pelo próprio sujeito. Para boa parte deles, é necessário estar sempre em busca de novos conhecimentos. Em sua opinião, a formação universitária que lhes foi oferecida não foi suficiente para proporcionar segurança em relação aos conhecimentos adquiridos; e, ao reconhecer a responsabilidade pela formação do aluno, percebem a importância da busca constante por conhecimentos que eles próprios admitem não serem novamente aqueles relacionados à prática. Estas considerações parecem compatíveis com a ideia de construção gradual e evolutiva do conhecimento na qual, além da emergência de novos conhecimentos, a constante reelaboração de conhecimentos pessoais tem fundamental importância.

Vemos em Novak (1991, p. 219) que "a compreensão nunca é completa, se trata de um processo reiterativo no qual nos movemos gradualmente de uma menor para uma maior compreensão até chegar ao ponto em que novas interrogações ampliam a fronteira da mesma”. Não temos a certeza de que os alunos se referem à busca do conhecimento conscientes desta construção progressiva, mas, mesmo de maneira intuitiva, eles parecem perceber a característica dinâmica e processual da aprendizagem pessoal. Apesar da dificuldade de controle, as estratégias metacognitivas são utilizadas para facilitar a construção de conhecimentos e exercitar sua transferência a outros contextos. Para Barth (1996, p. 211), "a meta-cognição tem por objetivo alargar o campo de consciência do educando e, portanto, a sua capacidade para reutilizar o que sabe em contextos diferentes".

Quatro alunos, em suas respostas a esta entrevista, afirmam que "aprender a aprender" além de interessante do ponto de vista da aprendizagem profissional é mais importante ainda por se tornar uma "aprendizagem para a vida". Parece-nos que, durante o caminho empreendido, estes alunos começaram a se questionar não somente a respeito de seu papel na construção do próprio conhecimento, mas também sobre sua função social, enquanto membros da sociedade e futuros professores. Começam a ensaiar a transferência dos saberes, de maneira deliberada, a outros contextos. Barth chama esta transferência consciente de "transferência por cima". Em suas palavras:

[...] primeiro ela não é automática, mas produz-se de forma consciente, temos que abstrair um objetivo de conhecimento de um dado contexto, generalizá-lo e utilizá-lo em outro contexto. Trata-se, portanto, de um esforço intelectual, conscientemente desejado pela pessoa que o faz. (BARTH, 1996, p. 212)

Pode-se dizer que estes alunos encaminham-se ao que parte deles chama de autoformação. Esta característica aparece nas falas de vários alunos. Para eles, a autocrítica, gerada em diversos momentos vivenciados, fez com que passassem a pensar mais detidamente nas concepções que eram tidas como verdadeiras. Eles admitem que isto ficou mais claro quando perceberam nas suas próprias dificuldades, ao elaborarem atividades de ensino, as possíveis dificuldades dos alunos a quem elas se destinavam. 
Os sujeitos parecem apresentar um início de percepção da necessidade de buscar alternativas pessoais, não só para a própria aprendizagem, mas - e para o propósito do trabalho desenvolvido o mais importante - para a construção de alternativas didáticas pessoais. Parece-nos que, ao longo das atividades propostas, os alunos passaram por um processo de uma percepção inicial em que se evidenciava uma parcela maior de responsabilidade pela formação depositada no formador e leve percepção da necessidade de autoaprendizagem, para uma percepção refletida e consciente, além da transferência desta responsabilidade para si próprios. Para Porlan e Rivero (1998) isto trará um acréscimo ao desenvolvimento profissional autônomo: "Este controle tem uma dupla potencialidade, por um lado, um incremento da autonomia e das possibilidades de desenvolvimento autodirigido e por outro a possibilidade de extrair por analogia, conclusões acerca da aprendizagem dos alunos" (PORLAN e RIVERO, 1998, p. 167).

Pode-se dizer então que encontramos, ao longo do discurso dos alunos e ao longo dos textos ${ }^{5}$ analisados, um padrão semântico comum compartilhado por todos os sujeitos da pesquisa. Os alunos utilizam a linguagem apresentando um padrão evolutivo que indica a elaboração de comparação e inter-relações entre os diferentes textos, associando as novas significações elaboradas àquelas anteriormente construídas. Para Lemke, estes significados vão se ajustando a padrões temáticos familiares de maneira a produzir sentido. Em suas palavras: “[...] Os padrões temáticos se vinculam facilmente uns com os outros e podemos expandir em muitas direções diferentes o contexto no qual interpretamos algo" (LEMKE, 1996, p. 106).

Se pudermos identificar as diferentes instâncias do padrão temático aqui discutido, elas podem ser assim representadas:

Entrevista 1:

É necessário aprender a ser professor; É preciso adquirir novos conhecimentos.

Avaliação 1:

O conhecimento é construção própria, demanda responsabilidade e gera autonomia.

Avaliação 2:

Aprender é querer; Autoaprendizagem e investimento na própria formação.

Entrevista final:

Aprendizagem a partir da reflexão; Aprender a aprender; Busca pessoal e transferência a outras situações.

Parece-nos que, de maneira evolutiva e gradual, os alunos percebem sua aprendizagem inicialmente como um processo de construção própria, onde o principal responsável ainda é o professor, e passam a uma compreensão mais elaborada, cuja construção demanda

\footnotetext{
${ }^{6}$ Textos entendidos aqui a partir dos conceitos da semiótica social proposta por Halliday (1998). 
autorresponsabilidade. Na sequência, acrescentam a componente motivação na forma de desejo pessoal e autoaprendizagem refletida, desenvolvendo uma preocupação com a transferência destes saberes elaborados a uma situação de trabalho na qual este só fará sentido se for colocado a serviço da aprendizagem dos alunos.

\section{Considerações finais}

[...] Uma realidade social (ou uma "cultura") é, em si um edifício de significados, uma construção semiótica. (HALLIDAY, 1998, p.10)

Voltar o olhar para esta construção implica imergir no conjunto das múltiplas percepções individuais que se entrelaçam para dar forma à realidade. $\mathrm{O}$ trabalho aqui apresentado nos colocou frente a frente com a possibilidade de enveredar por um destes caminhos, focalizando uma única faceta do processo de formação de professores. Apesar de estar concentrada somente nas percepções dos indivíduos a respeito de seu processo de aprendizagem com base na aplicação de uma metodologia diferenciada (metodologia investigativa ou investigação orientada), a análise dos dados apresentada nos dá uma amostra da complexidade e variedade destas percepções.

Algumas importantes implicações para os processos formativos podem ser vislumbradas com base no processo descrito e nos resultados apresentados:

- As concepções apresentadas pelos sujeitos nos diferentes momentos evidenciam uma "realidade social", como nos diz Halliday, que se não for observada e percebida de maneira despojada de preconceitos, pode revelar uma imagem distorcida da realidade.

- É possível que estas concepções evoluam durante um processo formativo e isto ficou evidenciado por meio do levantamento das percepções geradas pela proposta a que os sujeitos foram submetidos e ao processo reflexivo gerado por ela.

- O processo de reflexão gera nos sujeitos uma percepção mais adequada de suas estratégias de aprendizagem e o reconhecimento de que são capazes de 'aprender a aprender', selecionando as melhores estratégias para cada situação e percebendo que elas são válidas somente para cada um deles, pois são resultado de um processo de construção pessoal.

Finalmente, podemos sugerir que os responsáveis pelos cursos de licenciatura, nas suas diversas áreas, admitam a necessidade de rever a organização básica e o relacionamento entre as disciplinas científicas dos núcleos de conteúdo específico e pedagógico, de maneira a promover uma maior integração entre elas, proporcionando ao processo formativo um trabalho realmente integrado. Isto atenderia as necessidades básicas de formação de um profissional que percebe a importância da construção de um sólido conjunto de conhecimentos (científicos e pedagógicos integrados) para a realização do trabalho pedagógico e capaz de se manter em constante autoformação.

Em relação às políticas públicas de formação, cabe ressaltar a necessidade de investimento na "formação de formadores", ou seja, oferecer oportunidades aos docentes universitários responsáveis pelos processos formativos nas licenciaturas, de participação em estudos e pesquisas que favoreçam a própria formação. Oferecer, também, aos professores de Ensino Médio, que recebem os alunos de licenciatura para estágios, oportunidades de refletir sobre 
A influência dos processos que buscam ...

suas responsabilidades em relação ao processo formativo destes licenciandos, além de oportunidades de formação continuada específica para este fim.

Aprender quer dizer criar um significado entre as inúmeras impressões que se impõem aos nossos sentidos. Se este significado se cria na relação com o outro e no diálogo, os sujeitos desta pesquisa foram capazes de construir e reconstruir o significado de aprender com o ponto de chegada na percepção da responsabilidade pelo próprio processo de aprendizagem e na necessidade de aplicar estes conhecimentos a novos contextos-ação, ou seja, na atividade profissional.

\section{Referências}

ANDRÉ, M. E. D. A. Pesquisa formação e prática docente. In: . (Org.). Papel da pesquisa na prática de professores. Campinas: Papirus, 2002. p. 55-69.

BARTH, B.-M. O saber em construção. Lisboa: Instituto Piaget, 1996.

CHAUÍ, M. Convite à Filosofia. São Paulo: Ática, 2000.

CUNHA, M. I. O futuro é hoje: o desafio político-epistemológico do ensino superior na sociedade contemporânea. In: ENCONTRO NACIONAL DE DIDÁTICA E PRÁTICA DE ENSINO, 7., 1996, Caxambu. Anais... Caxambu: 1996. p. 382-94.

ESPITIA, E. C. La fenomenologia como alternativa apropriada para estudiar los fenômenos humanos. Revista Investigación y Educación en Enfermería, Medelin, v. 18, n. 1, 2000. Disponível em: <http: // fone.Udea.edu.o/revista/mar 2000/ Fenomenologia.html>. Acesso em: 13 jul. 2005.

FONTANA, A.; FREY, J. H. Interviewing: the art of science. In: DENZIN, N. K.; LINCOLN, Y. S. (Eds.). Handbook of qualitative research. Thousand Oaks: Sage Publications, 1994. p. 361-73.

HALLIDAY, M. A. K. E1 lenguaje como semiótica social: la interpretación social del lenguaje y del significado. Bogotá: Fondo de Cultura Económica, 1998.

LAFORTUNE, J.; SAINT-PIERRE, L. A afectividade e a metacognição em sala de aula. Lisboa: Horizontes Pedagógicos/Instituto Piaget, 2001.

LEMKE, J. L. Aprender a hablar ciencia: lenguaje, aprendizaje y valores. Barcelona: Paidós, 1996.

MARTINS, J.; BICUDO, M. A.V. A pesquisa qualitativa em psicologia: fundamentos e recursos básicos. São Paulo: Moraes Editora, 1994.

MOREIRA, D. A. O método fenomenológico na pesquisa. São Paulo: Pioneira Thomson, 2002.

NOVAK, J. D. Ayudar a los alumnos a aprender como aprender. Enseñanza de Las Ciencias, Madri, v. 9, n. 3, p. 215-28, 1991. 
PEREZ GÓMEZ, A. O pensamento prático do professor: a formação do professor como profissional reflexivo. In: NÓVOA, A. (Org.). Os professores e sua formação. Lisboa: Dom Quixote, 1992. p. 95-114.

PORLAN, R.; RIVERO, A. El conocimiento de los profesores: una propueta formativa en el area de ciencias. Sevilla: Diada Editora, 1998.

POZUELOS, F. J. Formación en centro y mejora de la enseñanza. In: CAÑAL, P. et al. (Orgs.). Investigar en la escuela: elementos para una enseñanza alternativa. Sevilla: Díada Editora, 1997. p. 285-94.

REZENDE, A. M. Concepção fenomenológica da educação. São Paulo: Cortez/ Autores Associados, 1990.

SCHNETZLER, R. P. Práticas de ensino nas ciências naturais. desafios atuais e contribuições da pesquisa. In: ROSA, D. E. G.; SOUZA, V. C.; FELDMAN, D. (Orgs.).

Didáticas e práticas de ensino: interfaces com diferentes saberes e lugares. Rio de Janeiro: DP\&A, 2002. p. 205-22.

SCHÖN, D. A. Formar professores como profissionais reflexivos. In: NÓVOA, A. (Org.). Os professores e sua formação. Lisboa: Publicações Dom Quixote, 1992. p. 77-91.

TARDIF, M. Saberes profissionais dos professores e conhecimentos universitários: elementos para uma epistemologia da prática profissional dos professores e suas conseqüências em relação à formação para o magistério. Revista Brasileira de Educação, São Paulo, v. 13, n. 13, p. 5-24, 2000.

VIEIRA DA SILVA, R. I. A influência das propostas curriculares na formação de professores de química. 2006. 118f. Monografia (Conclusão de Curso de Licenciatura em Química) - Universidade Estadual Paulista, Bauru, 2006.

ZEICHNER, K. M. A formação reflexiva de professores: idéias e práticas. Lisboa: Educa, 1993.

ZULIANI, S. R. Q. A. Prática de ensino de química e metodologia investigativa: uma leitura fenomenológica a partir da semiótica social. 2006. 288f. Tese (Doutorado em Educação) - Universidade Federal de São Carlos, São Carlos, 2006.

A utilização da metodologia investigativa na aprendizagem de química experimental. 2000. 287f. Dissertação (Mestrado em Educação para a Ciência) - Faculdade de Ciências, Universidade Estadual Paulista, Bauru, 2000. 


\section{Apêndices}

A) Entrevista inicial - Protocolo:

a. Que aspectos deveriam ser levados em consideração durante o processo de formação inicial para uma formação docente de qualidade?

b. Que aspectos já trabalhados em sua formação inicial serão determinantes para sua atuação profissional?

c. O que você indicaria como determinante para a inclusão de determinadas estratégias de ensino num plano de aula ou numa atividade de ensino?

d. Que fatores determinam a eficácia da atuação do professor de Química?

e. O que você sugere como estratégia facilitadora para o processo de ensino e aprendizagem?

f. Que fatores determinam o seu próprio processo de aprendizagem?

g. Que relações existem entre sua aprendizagem e a elaboração de estratégia de ensino para o aluno?

\section{B) Avaliação inicial: Protocolo - Responda às questões abaixo:}

a. Em sua opinião, qual o propósito do trabalho desenvolvido nesta disciplina?

b. Se houve algum, quais foram os efeitos provocados em suas convicções pelas ações desenvolvidas no curso até o momento? (bons e maus efeitos)

c. Quais os efeitos de um trabalho desenvolvido desta maneira para a formação de futuros professores? d. Você pensou sobre participar desta disciplina? Se afirmativo, no que e por quê? Se não pensou, por que motivo?

e. Você teria algum outro comentário ou avaliação para fazer a respeito do projeto?

\section{C) Protocolo da Avaliação Final PEQ II (escrita)}

Este instrumento tem por objetivo avaliar o curso, e não o seu desempenho enquanto aluno durante a sua participação nele. Trata-se também de uma importante fonte de dados para o trabalho de pesquisa que estamos realizando. Portanto, sua sinceridade ao respondê-lo é de fundamental importância. Responda não com as palavras que acredite que eu queira ouvir, mas com as que você realmente quer dizer.

1) Em relação ao trabalho desenvolvido nesta disciplina, indique (procure justificar de maneira mais explícita possível suas opiniões):

a. O que eu (você) aprendi (em relação ao ensinar e aprender, aprendizagens pessoais, ao que devo ou não adotar etc)?

b. Como eu (você) aprendi (de que maneira, com ou sem novidades, de maneira interessante ou enfadonha etc)?

c. Com quem eu (você) aprendi (colegas, discussões, pesquisas, professor etc)?

d. O que eu (você) não aprendi (e poderia ter aprendido ou deveria ser oferecido)?

2) Emita suas opiniões sobre as seguintes afirmações (concordando, discordando ou opinando de forma diversa) (Você poderá fazer um único comentário reunindo as afirmações existentes nas questões a, b e c, ou comentar item a item):

a) Formação de professores:

- O professor deve instigar o aluno na busca pelo conhecimento;

- Para ensinar, o professor não precisa estudar;

- O professor deve elaborar, planejar e testar uma atividade de ensino antes de aplicá-la com os alunos;

- A teoria sobre o ensino não é importante. O que importa é a prática; 


\section{Zuliani, S. R. Q. A.; Hartwig, D. R.}

- Ensinar é um dom;

- Para formar um bom professor, é necessário, além da base teórica, obtida nas disciplinas, oferecer-lhe modelos de ensino.

\section{b) Ensino de Química:}

- Utilizar temas para desenvolver o ensino de Química pode ser um problema para conseguir "dar conta" do conteúdo previsto;

- O uso de temas para o ensino implica estar atento aos conceitos implícitos a eles (temas);

- Usar a experimentação é a melhor maneira de ensinar Química;

- Utilizar temas evita que o aluno aprenda somente o conteúdo pelo conteúdo;

- Aprendemos mais se buscamos o conhecimento.

\section{c) Planejamento de Ensino:}

- O professor precisa se autoavaliar, analisar criticamente seu planejamento, confiar em si mesmo e aprender com os alunos;

- A construção coletiva de atividades de ensino pode auxiliar o trabalho do professor;

- O planejamento é uma atividade desnecessária, pois o conteúdo a ser ensinado é sempre o mesmo.

\section{D) Entrevista final - Protocolo}

a. A disciplina atendeu a suas expectativas em relação à proposta para a formação docente. Quais os aspectos mais importantes? Justifique?

b. Como você vê a elaboração de estratégias de ensino após as discussões levadas a termo na disciplina? O que é importante levar em consideração ao elaborá-las?

c. Relacione o que você aprendeu ou o que foi discutido durante as aulas e seu processo de aprendizagem.

d. Que relações existem entre sua aprendizagem e a elaboração de estratégias de ensino.

Artigo recebido em setembro de 2008 e aceito em abril de 2009. 